\title{
Self-Guided Field Trips for Students of Environments
}

\author{
Graham A. Moore \\ The University of Melbourne \\ email: grahamam@unimelb.edu.au \\ Roger G. Kerr \\ The University of Melbourne \\ email: rgkerr@unimelb.edu.au \\ Roger G. Hadgraft \\ The University of Melbourne \\ email: roger.hadgraft@unimelb.edu.au
}

\begin{abstract}
The Bachelor of Environments is one of the New Generation Degrees within the Melbourne Model at the University of Melbourne. It is intended to provide a platform of study for students in a number of disciplines and to provide a source of breadth study for students from other New Generation Degrees. Providing opportunities for students to undertake field trips while studying first year subjects in the Bachelor of Environments is one of the more challenging issues for subject designers. How can large cohorts of students gain practical exposure to various aspects of the environment? Although this is typically done using traditional site visits and fieldwork with a high staff/student ratio, our goal has been to design and develop resources to enable small groups (3 or 4) to make self-guided visits to sites close to campus. The students are guided by multimedia resources to examine and interpret aspects of the site that relate to their on-campus learning. One critical issue in the success of these activities has been a proper risk assessment and provision for immediate assistance if required. These self-guided field trips are an important way of ensuring an engaging learning experience, even for large classes.
\end{abstract}

\section{Introduction}

Conventional site visits normally require a subject matter expert to discuss and interpret various features with the students. Even with small groups, of up to twenty students, this does not work very well because not everyone can hear or see the guide. As a fundamental part of this project, we developed multimedia materials (audio, graphics and video) that the students can take on tour with them to take the place of the subject matter expert. This allows site visits to be contemplated for large classes of hundreds of students.

The importance of the students being engaged in the exploration of concepts, issues and ideas often involves hands-on investigation into real world sites, issues and problems, and working collaboratively on relevant multi-disciplinary projects to which they can feel connected. It also requires the posing of significant questions that can be investigated (Cragg, 1998; Lord 2008).

We expect there will be an increasing demand for this style of engaging learning in large classes. This project set out to develop a method for self-guided field trips, so that it could be replicated across many subjects. We began by documenting our existing collective experience, combining resources and experiences that existed across three Faculties. 


\section{Stage 1 - Developing a Prototype}

Instances of remote field trips in the literature proved to be most fruitful in the case of virtual tours, many of which exist on the internet, for structured tours of places such as museums or national parks. For example, tours that contain information as PDF files can be loaded on mobile devices (Anon, 2008a) or audio players (Bari and Bari, 2008b). In these, there is more emphasis on information transfer rather than learning new concepts.

One example of a self-guided trip is Gardner \& Jacobs (2005) where students were sent off to study structural forms in the Australian Technology Park in Sydney with printed instructions and diagrams. In another case, students chose their own field trips to fit their intended project work (Hadgraft \& Goricanec, 2007).

The feasibility and pitfalls of podcasting and various other mobile devices, as multimedia platforms for guided site visits, was investigated in this project. It was decided that the narrative aspect of the selfguided site-visits was able to be effectively managed through these devices, and we already had similar experience in other multimedia projects.

Assessment and provision of effective feedback was also considered and it was determined that this would be possible through the use of the (Learning Management System: LMS) and the wiki tool; this was also the basis for providing effective feedback to individual groups.

We interviewed staff already conducting site visits for students to ascertain the type of learning objectives that they are achieving and worked closely with the academics designing the first year subjects (in particular Natural Environments) to develop evaluation tools and analytical methods for the learning materials.

We then focused on the development of risk assessment and management strategies for the proposed selfguided site visits. While the site visits are planned to take place in public places, there are risks to the students, and potentially to the sites if all students go to the same site. These risks require management from the University's point of view (Anon, 2008b) as well as developing the students' ability to recognize and manage risks for their own well-being, for example, during travel to and from the sites and at the sites. Conducting risk management is an important graduate attribute. Consequently, protocols for risk management became an integral part of this project, informed by the relevant standard (Standards Australia, 2004).

\section{Technology for making files for mobile devices}

A small survey of students enrolled in one subject was conducted in September 2007 to determine the types of mobile electronic devices that they own. Our conclusions from this survey were that it was highly likely that students either owned a device for listening to audio files, or if they were placed in groups of two or more, would almost certainly have someone in the group who would have an audio capable device. Similarly, if students were to be formed into groups, it would be quite likely that groups could be formed such that one of the group members could supply an audio and image capable device.

For the prototype exercise, a Macintosh (Macbook Pro) running standard Mac OS software was used to prepare the files. Images were managed in iPhoto, while Garage Band was used to record and edit the narration and match the track to images. These two items of software are provided free with Mac OSX. A USB headset was used to improve the clarity of the voice recording compared to that achievable with the built-in microphone. A selection of short public domain music tracks were supplied as part of the Garage Band software that were convenient for making a more professional sounding resource.

After creating a file in Garage Band it can be exported in MP4 format which allows both audio and image tracks for display on devices such as Apple iPods. Typical MP3 players cannot play MP4 files but conversion utilities are available to convert MP4 to MP3 format. The resulting file is stripped of its images. Another file type, GP3, is commonly used on G3 mobile phones. A further piece of Mac 
software, iMovie, can import an MP4 file and export as a GP3 file. One option that could not be easily achieved with this freely available software was a file with a combination of audio, still images and video images. Garage Band could produce audio plus video, but not a mixture of all 3 formats.

We found that it was more convenient for students if multiple smaller files were created rather than one large file. For the prototype, we made files of around two to four minutes having discovered that longer files were unwieldy to listen to and move around in with player software that did not support bookmarks or chapter markers. To allow students to test their devices we made short files (around 10 seconds) in each of the formats that students could quickly download to test their devices.

\section{Stage 2 - The Prototype}

A prototype of a self-guided site visit was created in October 2007 for a group of around twenty-four postgraduate students. The prototype included a full set of resources for students to investigate water sensitive urban design for stormwater management. To support the visit, pre-visit activities, such as transport planning, risk assessment investigations and management, and downloading of audio and/or image files were made available to the students before undertaking the visit. The actual site visit involved a simulation of a self-guided visit.

The lecturer, Graham Moore, followed the main group of students as an observer, while Roger Kerr accompanied the group as an education researcher who conducted interviews during the visit to record experiences with the format. Student assessment of the visit was limited to taking a group photo at one of the field sites, because the purpose of the site visit was primarily to provide background information for a design assignment that was separately assessed.

Students were provided with both electronic and paper based files to describe each observation point for the site visit. Audio files were MP3 files generally of a few minutes duration. Images from Google Earth were provided to assist navigation, along with scenes at each site to help students orient themselves. The printed files included the same images as provided electronically along with the full script for the audio file. The printed files extended to eleven pages. Electronic files including images and audio (M4A format) were provided in six files totalling about $12 \mathrm{MB}$ and could be played on devices such as iPods and some G3 mobile phones. The audio-only files were in MP3 format and were of similar size.

The mounting of a successful and safe learning experience is not a trivial exercise. In particular, the need to involve the students in the planning stages of the field visit is much greater than would traditionally be the case. This can be seen as either a significant barrier or an opportunity for students to practice the important skill of risk assessment, expected of all professionals. A concept map of the prototype is shown in Figure 1.

The prototype experience was very different for the lecturer. There was no pressure to narrate or explain areas of the site and merely casual observations were made of the student activity. There were only eight questions fielded from twenty-five students over the course of the activity which took about one and a half hours at the site. The expectation was that students would have taken the opportunity to ask questions while the lecturer was present; however, this was not the case. We concluded that the material produced to accompany students on the task was sufficiently comprehensive. Prior to this "self-guided" visit, the field trip would have been conducted in a similar way to a guided tour of the site.

\section{Stage 3 - The Self-Guided Field Trip}

Natural Environments was the subject chosen for the first full-scale trial of the concept of the self-guided field trip with 260 students. The first step in the process was to develop a field trip using the framework established in the prototype. The prototype was adapted with the assistance of Dr Tony Weatherley, subject coordinator, and Mark Dixon, senior tutor, using an established field trip to the Royal Botanic 
Gardens (Melbourne) in the subject of Global Ecology (from the School of Anthropology, Geography and Environmental Studies).

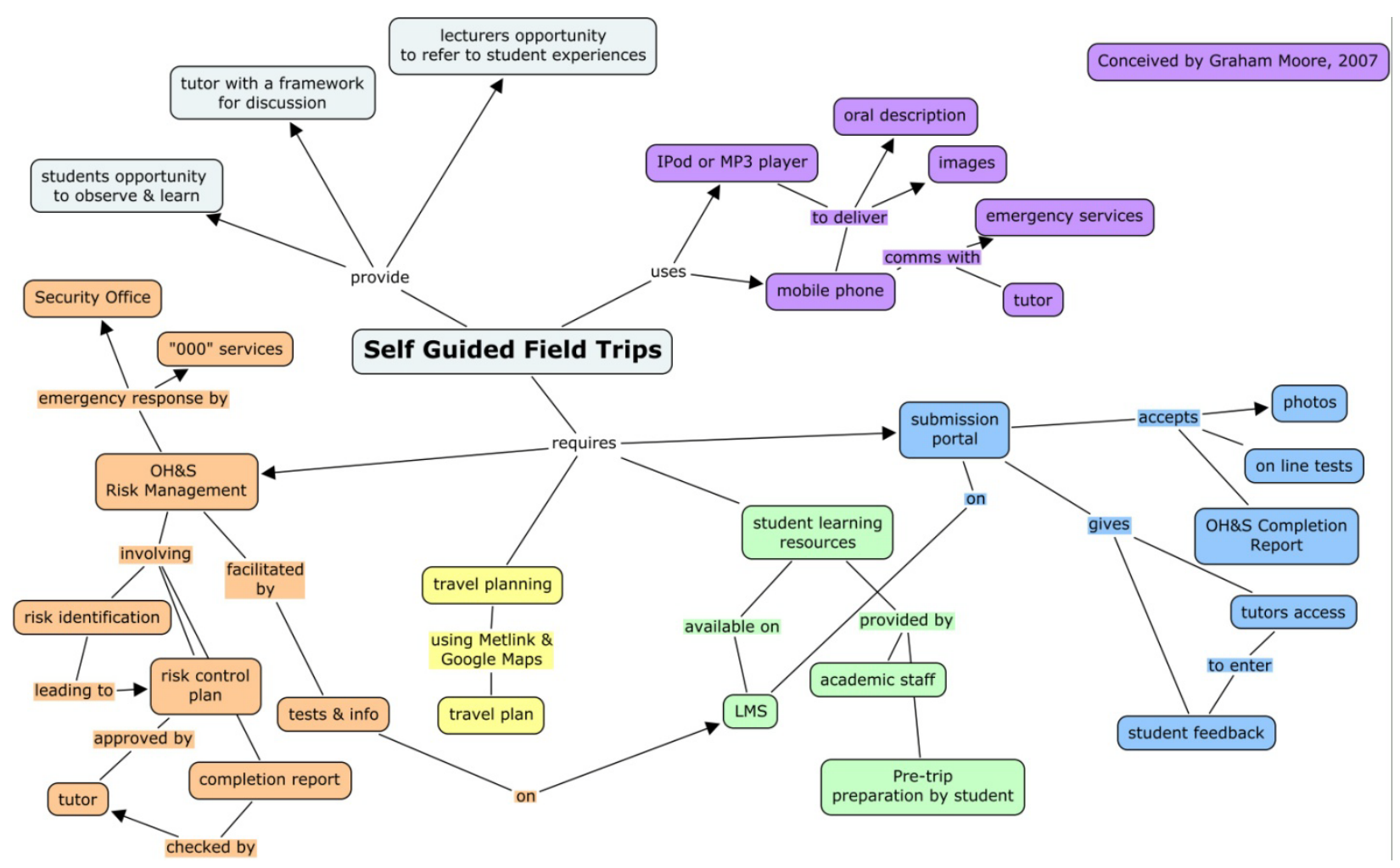

Figure 1. A concept map for the prototype self guided field trip.

On selection of the Botanic Gardens as the site to visit, we needed to develop a rationale and some key learning objectives, before setting out to compile the various multimedia components required. The selfguided field trip was planned to be introduced during week four of the semester. Once tutorials had begun, students groups (of four) were formed with the view to completing the trip either during the semester break or in the week that followed.

The Learning Management System (LMS) contained all of the elements of the self-guided field trip. A link was made within the LMS to the website for the trip. It contained various components, in particular the field trip overview and rationale, including the pre-trip planning procedures, risk assessment requirements, files to downloaded to mobile devices, wiki requirements and an online assessment (quiz).

The Pre-Trip planning mainly consisted of the Environmental Heath and Safety (EHS) issues that the prototype had established. Advice regarding emergency response was also included on the website. Students were also requested to check and update (if required) all of their emergency contact details by using the link to student services. All elements of the pre-trip planning procedures were compulsory for all students before attending the trip. The procedures included two online quizzes that students had to successfully complete.

On the LMS, students were requested to test their phone, player or iPod using test files. The test files were created as in the prototype. Video files were produced with the assistance of Dr Ian Thomas, one of the lecturers for the Ecosystems module of Natural Environments. He was filmed on location at the Botanic Gardens where he outlined the learning objectives and made reference to the applicable sections 
of the Gardens that the students would be required to explore during their visit. The video files were produced so that students would have a preparatory understanding of the requirements of the field trip before undertaking the field trip which meant that the video was able to be viewed on the LMS website or downloaded to a video player. The video was broken into five (5) minute segments and was produced using Power Director 6 [http://www.cyberlink.com/multi/products/main_4_ENU.html] on a Windows platform. Trip files were produced for the formats as per the test files.

We conducted an online survey on completion of the field trip where it was concluded that the self-guided aspects of the trip were a complete success with seamless effect. The data from the survey (completed by 95 students) clearly shows that the mechanics of this activity were easily handled by the majority of students, however, the EH\&S aspects were the cause of some concern, primarily because students found the online quiz difficult to complete.

\section{Botanic Gardens Self-Guided Field Trip Survey: Results}

Question 1: The EH\&S link was considered an essential component to ensure a safe tour. I found the EH\&S information useful.

*Average Response: 4 (Agree)

Question 2: The EH\&S assessment requirements were clearly explained within the pre-trip planning section.

Average Response: 3 (Neither Agree nor Disagree)

Question 3: The risk assessment quizzes were easy to understand and complete.

Average Response: 2 (Disagree)

Question 4: Did you make use of the link to the Botanic Gardens official website?

Yes $(60 \%)$

No (40\%)

Question 5: I downloaded the complete program of Dr Ian Thomas's video regarding the relevant points of the Botanic Gardens Tour and found it most useful as part of my pre-trip planning.

Average Response: 4 (Agree)

Question 6: I found the wiki was most useful in helping complete the Botanic Gardens Tour.

Average Response: 4 (Agree)

Question 7: Consider the link to the various types of files available to refer to and subsequently download to a mobile phone or music player. I found these files useful. If you did not copy the files to an appropriate mobile device, answer not neither agree nor disagree.
Average Response: 4 (Agree)

Question 8: The following two questions (Question 8 and Question 9) refer to the learning objectives.

I am able to recognise similarities in structural form of vegetation from different parts of the world which have similar climates. I am able to distinguish the major floristic differences between regions despite such structural similarities.

\section{Average Response: 4 (Agree)}

Question 9: I am able to identify the ways that plants have adapted to their environments and their unusual geographic distributions.

Average Response: 4 (Agree)

* Average Response: This is the average of responses 1 to 5 (1: Strongly Disagree, 2: Disagree, 3: Neither Agree nor Disagree), 4: Agree, 5: Strongly Agree).

Question 10: Do you have any additional comment(s) to make in relation to any of the organisational elements of this field trip? If so, please type your response below.

\section{Sample Comments}

The trip was well organised. The online videos and podcasts were very helpful, however sound and image quality could have been improved. I found the 1st EH\&S too complex, time consuming and could have been organised better. The audio tour was very helpful. I thought being able to get out of the lectures and tutes, actually seeing this nature that people were talking about was a really good way to learn.

Figure 2. Survey Results for Semester 12008 Natural Environments Self-Guided Field Trip 


\section{Summary}

The main question to ask throughout is: How do we best develop this type of learning activity? We have included the key points in an attempt to best summarise how to produce a successful self-guided field trip. In doing so, there are several questions that need to be asked before the concept is considered. For instance, has this subject contained a field trip as part of the previous related curriculum? Does a field trip suit the subject content?

Once the rationale is established and the self-guided field trip has been verified as being a key component of the curriculum, it is a good idea to seek out any field trip that may have been used in the past that may best suit the subject. This makes the process somewhat easier to develop if there is an existing field trip that can be adapted. In our experience, we chose to adapt a well resourced field trip at an easily accessed location within a reasonable proximity to the University (no more than 20 minutes by public transport).

The Environmental Health and Safety considerations are generic enough to require a very small amount of alteration depending on the location. It must be noted that careful consideration was given to the obligations to both the students and the University with regard to any implications arising from associated risks. In preparing the risk assessments we consulted with the University's EH\&S manual were it was concluded that before commencement of any visit that it was imperative for all participants to acknowledge that they have understood the issues and would make every effort to comply with the University's EH\&S Manual of which an extract was referred to.

Some of the key points to consider when producing a successful self-guided field trip:

- Establish achievable learning objectives for the task.

- Choose an appropriate place for the students to visit. Consider adapting a field trip that has been previously conducted for the subject.

- Produce a risk assessment of Environmental Health and Safety (EH\&S) issues.

- Develop appropriate guide material for the students (video and audio). Make this available in a range of formats: for audio; mp3, m4a, for video; 3GPP (mobile phones), MPEG-4 (iPhone), m4v (iPod) MOV (Quicktime), WMV (Windows Media Player).

- $\quad$ Outline possible mobile technology for use by students in the field and tailor the support material.

Producing effective support material requires a certain degree of competence in handling the various technologies available to use. In this case, a total multimedia approach was taken so that the end result could be transferred to appropriate mobile devices. The predominant use of audio and video enabled us to provide a reasonable simulation of the conditions that the students could expect on their site visit.

\section{Example files}

A set of example files is available at: http://www.eng.unimelb.edu.au/elu. Click on Project resources.

\section{References}

Anonymous , 2008b. Environmental Health and Safety Manual. http://www.unimelb.edu.au/ehsm/ Accessed 2 August 2008

Anonymous, 2008a, Field Trips. http://www.earthmaps.com/fieldtrips.htm accessed 2 August 2008.

Bari, J and Bari, L, 2008. Philly MP3 - The Constitutional Walking Tour. http://www.theconstitutional.com/phillymp3/sample.html Accessed 2 August 2008.

Cragg, Paul B. 1998 Site Visits as a Teaching Method in Information Systems Courses. In: Proceedings of the International Academy for Information Management (IAIM) Annual Conference (13th, Helsinki, Finland, December 11-13, 1998); see IR 057374. 
Moore, Kerr \& Hadgraft: Self-guided field trips for students of environments

Gardner, A. and B. Jacobs (2005). Go and see and touch and feel - An introductory case study for Civil Engineering students. Proceedings of the 2005 ASEE/AaeE 4th Global Colloquium on Engineering Education. D. Radcliffe and J. Humphreys. Sydney.

Hadgraft, R. G. and J. L. Goricanec (2007). Student Engagement in Project-Based Learning. 1st International Conference on Research in Engineering Education. Honolulu, HI.

Lord, T and Orkwiszewski, T. 2006 Moving from Didactic to Inquiry-Based Instruction in a Science Laboratory. American Biology Teacher; v68 n6 p342-345

Standards Australia. 2004 AS/NZS 4360:2004 Risk Management.

Copyright $\odot 2008$ Graham A. Moore, Roger G. Kerr and Roger G. Hadgraft: The authors assign to AaeE and educational non-profit institutions a non-exclusive licence to use this document for personal use and in courses of instruction provided that the article is used in full and this copyright statement is reproduced. The authors also grant a non-exclusive licence to AaeE to publish this document in full on the World Wide Web (prime sites and mirrors) on CD-ROM and in printed form within the AaeE 2008 conference proceedings. Any other usage is prohibited without the express permission of the authors. 